\title{
From around the world
}

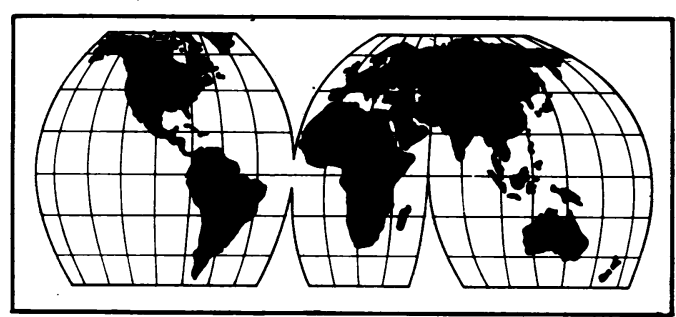

The British scene

The government's white paper on the Health Service has dominated medical thinking and provided the main topic of conversation at dinners and cocktail parties when doctors gather over the past 12 months. The legislation is likely to proceed regardless of the colour of the government replacing the present administration. One aspect of the paper which has been welcomed by the profession has been the emphasis on audit-a need to collect information on what we do and how we do it. Although the NHS white paper specifically requests 'medical audit', this is felt to be too restrictive for a multidisciplinary specialty like rheumatology. Particular problems beset the rheumatologist in this area, not least that most hospital audit centres on inpatients, whereas the majority of rheumatological practice is outpatient based.

A flurry of activity has arisen from the Royal College of Physicians of London, which has sponsored meetings on audit in conjunction with the British Society for Rheumatology. Although this seems an attractive approach, as far as the management of chronic illness is concerned one has to ask whether the expenditure of effort is commensurate with the benefits gained. The evaluation of rheumatic problems is altogether different from the analysis of surgical procedures. We only have crude outcome measures, poorly fitted for such analysis. Moreover, there are no agreed protocols for the treatment of diseases as complex as rheumatoid arthritis. On the other hand, it could be argued that much of the clinical research we already do is sophisticated audit. The extensive clinical trials of antirheumatic drugs are just that. It is recognised that to implement the government's directives health service managers have an obligation to introduce data systems which include diagnostic and procedural information to all rheumatological services as a matter of urgency. As their salaries are in measure dependent on the money they save in the service, not the cash they expend on improving the lot of patients, this is likely to be whistling for the wind in most places. Many feel that the NHS is now largely in the hands of cost cutting accountants.

Another aspect of government intervention has been an attempt to increase the participation of general practitioners in the management of rheumatic patients. Linking financial rewards to such activities as attendance at postgraduate education courses, performance of minor surgery (this includes soft tissue and intra-articular steroid injections), and the organisation of miniclinics (10 homogeneous cases per clinic-for example, musculoskeletal pain) may promote this.

There is further anxiety about the government's cutback on' the funding of research. Already the Medical Research Council and the Science and Engineering Research Council have had their grants severely curtailed. The basis of funding of universities is now being altered fundamentally. Charities will have to absorb the university overheads; figures quoted have varied from $30 \%$ to $200 \%$ in different universities. The Arthritis and Rheumatism Council has taken important initiatives in this area. A further chair of rheumatology has been established at the University of Glasgow (the ARCMcCleod chair), to which Professor Roger Sturrock has been appointed. A career structure for basic scientists has been developed with the institution of intercalated $\mathrm{BSc}$ and $\mathrm{PhD}$ studentships, and senior research fellowships to supplement the already existing junior research fellowships.

$$
\begin{array}{r}
\text { V WRIGHT } \\
\text { Rheumatology and Rehabilitation Research Unit } \\
36 \text { Clarendon Road } \\
\text { Leeds LS2 9NZ }
\end{array}
$$

\section{America}

The invitation to write a piece for this 50th anniversary issue arrived on the same day as news that the hostages were being freed from Kuwait. All one could think of was Paul Dieppe-one of many British rheumatologists admired and beloved in the States-coming home. It was a cause for celebration. Our mutual joy reminds one of the many personal and intellectual ties between rheumatology in the United States and Britain and the vital role of scholarly journals in recording and fostering that relationship. The Annals as befitting a publication of the United Kingdom is a truly international journal. Where else could one learn about rheumatic diseases in the Third World (or the United States!) or read papers of substance from all the major centres in Europe, 
the Pacific Rim nations, the United States and Canada, and hopefully from Eastern Europe. The communication revolution wrought by telephones, distributed computer systems, Fax, connects us all, or it should. English is the universal language of science and thus a great responsibility rests on editors to cultivate publications from non-English speaking countries to ensure their timely and fair review and to acknowledge and translate ideas and contributions properly.

Arthritis and Rheumatism, which is the major publication for rheumatology in our country, has changed editorial leadership and since mid-1990 we have had a $30 \%$ increase in the number of manuscripts submitted, with most from outside the United States. The many papers which do not receive a sufficiently high priority score from the reviewers $(85 \%$ of submitted manuscripts are rejected) may fall into the category of not presenting new information, having only regional relevance (or the lack of an argument to explain the potential relevance to readers from other countries); or be case reports with unproved claims of primacy or lack of clinical details; or papers with weak English. The first two problems will improve, we surmise, as authors learn what the journal is looking for; the last could be improved greatly by better English translations before submission. It is our hope that we can encourage even more submissions from other countries, improve the responsiveness of the reviews, and increase the number of clinically relevant articles published. We look to the clinical journals from England as examples. Congratulations to the Annals of the Rheumatic Diseases and its readers on your 50th anniversary, and many more.

MATTHEW H LIANG Robert B Brigham Multipurpose Arthritis Center Department of Rheumatology 75 Francis Stree Boston, Massachusetts 02115

USA

\section{Belgium}

At the time of the celebration of the 50th volume of the Annals of the Rheumatic Diseases, Clinical Rheumatology-an international journal in continuation of Acta Rhumatologica Belgicais entering its 10th volume. At this time the format of the journals has been changed to please our increasing number of readers and to allow inclusion of extra papers dealing with the clinical aspects of rheumatology.

The field of rheumatology research interest in Belgium has always been broad but during the past 10 years has focused more and more on research into osteoarthritis and osteoporosis. At first glance it might seem surprising that bone and cartilage research go together. It is now widely realised that osteoarthritis and osteoporosis are multifactorial diseases and that aging and degeneration are not the major pathogenetic mechanisms. Furthermore, the inverse relation between osteoporosis and osteoarthritis points to intriguing questions and new research aspects. The advent of new measuring and imaging techniques, the new possibilities of cell and organ cultures, and the progress in molecule biology and knowledge about cytokines, lymphokines, and growth factors open up exciting new possibilities of elucidating the pathogenesis of the crippling conditions osteoarthritis and osteoporosis.

To further these changes of interest and new possibilities the initiative was taken to bring together scientists and clinical researchers in cartilage and bone by organisation of the first Eular workshop on bone and cartilage research, which will be held in Leuven, Belgium, 19-21 September 1991. We hope that this initiative will be repeated under the auspices of the Eular Standing Committee for Investigative Rheumatology along similar lines to the yearly workshops on the immunological aspects of rheumatology.

It was also from Belgium that the first meetings for health professionals in rheumatology were launched. The fourth meeting will be in Harrogate, Great Britain, 10-13 June 1992, organised by Dr H A Bird. Furthermore, in Belgium the first congress on art, history, and the antiquity of rheumatic diseases was organised by Professor T Appelboom.

All these events prove that a small country in the centre of Europe can have a central role, and we are proud of it. We will do our best to be a good host for all those who come to visit us.

J DEQUEKER

Arthritis and Metabolic Bone Disease Research Unit $K U$ Leuven

$U Z$ Pellenberg B-3212 Pellenberg Belgium

\section{Germany}

Before the official political reunification of both German states the rheumatological societies of east and west formed the common German Society of Rheumatology at the occasion of the 24th meeting in September 1990 in Hannover. Headed by $\mathbf{H}$ Zeidler, president of the German Society of Rheumatology, and M Zimmermann, president of the German, Austrian, and Swiss Society for the Study of Pain, this joint congress attended by an international audience displayed a great scientific standard. An innovation of the congress was an informative gathering organised by the committee for patient education of the German Society of Rheumatology (H E Langer, J M Engel).

The cornerstone for reunification of both German societies was layed down at the last congress of the DDR Society of Rheumatology in April 1990 in Gera, where its president, G Wessel, was honoured. He was succeeded by interim president $\mathbf{H}$ Häntzschel.

W Hartl, head of the rheumatology clinic in Aachen, retired and was honoured at a symposium with the Ernst-von-Bergmann medal. He was succeeded by E Genth, who successfully established the amino acid sequence of a monoclonal human IgA rheumatoid factor.

In Mainz K-H Meyer zum Büschenfelde investigated cellular and genetic requirements for pathogenesis of inflammatory synovitis. H H Peter, Freiburg, established a clinical and laboratory programme for diagnosis and treatment of systemic vasculitides. W L Gross, Bad 
Bramstedt and Lübeck, identified the ACPA ANCA target antigens. In Erlangen J R Kalden and associates promoted work on $T$ cells and immunogenetics of rheumatic diseases.

In Vienna, Austria, W Siegmeth investigated the different courses of rheumatoid arthritis and the influence of oestrogens and oral contraceptives. Osteoporosis research, disease modifying antirheumatic drugs in rheumatoid arthritis, and percutaneous application of non-steroidal anti-inflammatory drugs were studied by $H$ Brǒll and K Chlud. R Eberl, J Smolen, and G Partsch examined hyaluronate and cytokines in synovial fluids. Biochemical changes of cartilage caused by non-steroidal anti-inflammatory drugs, data on bronchial lavage, and measurement of free and bound anti-idiotypic antibodies in rheumatoid arthritis were presented by $\mathrm{G}$ Kolarz and $\mathrm{N}$ Thumb, Baden. $\mathrm{G}$ Klein, Saalfeld, was elected president of the Austrian League against Rheumatism.

In Switzerland W Müller, who established the rheumatology clinic of the University at Basle, continued his work on extra-articular rheumatism, basic research, and immunomodulators. He established the Institute for Research and Prevention of Rheumatic Diseases in Säckingen-Rheinfelden. In Zurich F J Wagenhäuser and $\mathrm{K}$ Fehr were interested in osteoarthritis, ankylosing hyperostosis, and immunosuppressive and immunomodulating treatment. K Fehr is president of the Swiss Society of Rheumatology.

In London G L Bach was elected president of the International Society for Rheumatic Therapy. On 1 January 1991 K Schmidt, University of Glesson, succeeded H Zeidler as the new president of the German Society of Rheumatology.

GERHARD L BACH
Klinik Auerbach
Heinrich Str 4
6140 Bensheim 3, Germany

\section{India}

It has been previously pointed out that an average Indian student of medicine has little exposure to rheumatology. This continues throughout his professional career. The Indian Rheumatism Association is fully aware of this, but it is only now that it has decided to tackle this problem systematically. It is obviously necessary to hold education programmes round the year at different places. India being a vast country, and the financial resources being meagre, it has been decided to seek the help of the pharmaceutical industry. It is heartening to note that many pharmaceutical firms have shown interest in such a joint activity. An education committee is now working on the details. It is planned to have structured continuing medical education programmes to ensure adequate and uniform coverage.

The first such programme is likely to be held by June. The content and quality of continuing medical education will be reviewed continuously. We watch with interest the success of this activity. If successful it will be an important step in the advancement of rheumatology.
An average Indian's concept of rheumatic diseases is vague at best. There is a general belief that allopathy has nothing to offer as there is no cure. The importance of joint protection and physiotherapy is not understood. In consideration of this, a public education committee has been formed along the lines of the continuing medical education programmes. This of course is a more difficult task and requires the participation of many agencies. It is felt that television and radio can play an important part. The television network in India has grown rapidly and covers almost the whole of the country. It will be necessary to organise talks, open forums, provide information booklets, to name but a few options. These will have to be in many languages, there being no lingua franca.

There have been sporadic attempts at epidemiological studies - for example, of rheumatoid arthritis and lupus. Recently, an all India based study on osteoarthritis and acute musculoskeletal syndromes has been completed (interestingly in collaboration with a pharmaceutical house-Pfizer India). The details of this study are still being analysed and will be reported fully in the next dispatch.

With increasing interest and availability of resources it is becoming apparent that one might look for rheumatic diseases peculiar to tropical countries as leprosy, tuberculosis, syphilis, worm infestations, nutrition, toxins, and haematological disorders can be responsible for rheumatic complaints. Already some younger members are becoming interested in this facet. We hope to learn more about these in coming years.

$$
\begin{array}{r}
\text { V R JOSHI } \\
\text { P D Hinduja National Hospital } \\
\text { and Medical Research Centre } \\
\text { Veer Savarkar Marg } \\
\text { Mahim } \\
\text { Bombay 400 } 016 \\
\text { India }
\end{array}
$$

\section{The Netherlands}

Several similarities can be seen in the development of rheumatology in Great Britain and The Netherlands. About 75 years ago attention was drawn to the rheumatic diseases by individual doctors in both countries. Since then they have stimulated each other in their endeavour to reach their scientific and medical goals. At the suggestion of Dr Jan van Breemen the International Society of Medical Hydrology founded a rheumatology committee in 1925 . One year later the national committee of the 'Ligue contre la Rheumatism' had already been founded in Holland, followed by the official institution of the international league in 1928. The Archives of Medical Hydrology and Acta Rhumatologica, the latter published in Holland, served as journals for scientific communication in the area of rheumatology. In addition, reports of international meetings were published in these journals. Both journals might be considered to be heralds of the Annals. For many years a statement could be found on the inside of the front cover of the Annals that the journal had 
the support of various international societies. Although this support is no longer officially conferred, the journal is recognised by many countries as a leader in its field. Its independence nowadays is a result of the quality of its contents. The Annals has not only been an outstanding scientific journal but it has always helped in postgraduate training by the educational style in which many articles were published.

In the early 1930s the first rheumatology clinics had already been opened in England and The Netherlands. The scientific basis for research in the rheumatic diseases was established after the war and resulted, in the ' $50 \mathrm{~s}$, in the founding of the first chairs in rheumatology in both Great Britain and The Netherlands.

Since that time many young Dutch doctors have received their scientific training in Great Britain, with Professor Willy Hijman as one of the first and Professor Hans Bijlsma and Dr Mieke Hazes as the most recent trainees; but the reverse has also happened. The close exchange of ideas and views between British and Dutch doctors has greatly contributed to the increased interest in clinical rheumatology and to the development of rheumatology research in The Netherlands. This development has been reflected in an increase in the number of Dutch contributions to international meetings and peer reviewed journals. The editorial board of the Annals has played a major part in this process.

We hope that the Annals will maintain its high international standard and typical British practical approach. We congratulate the board and publishers with the 50th anniversary of this journal. May this journal be as scientific and educational for doctors from all countries as it has been for the Dutch rheumatologist.

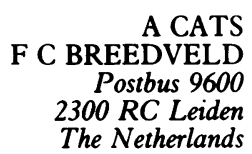

Scandinavia: Out of the mud ...

This contribution to the 50th anniversary celebration of the Annals takes its title from an absorbing article by W S Tegner in the first volume on the treatment of rheumatic diseases in Europe and the United States, based on six months' experience as a Sir Alexander Walker travelling research scholar. ${ }^{1}$ Dr Tegner spent a week in Sweden and was impressed by the practice of mud treatment at the spa in Varberg, supervised by my pre-predecessor, Gunnar Edström. The Varberg mud was very popular even in some university departments of medicine well into the 1960s when I was a house officer with Professor Waldenström, and it probably did not do much harm. In another spa in Nynäshamn Dr Sundelin focused on intensive physical training, a tradition that was reborn and used in formal trials in later years and is now claimed not only to improve fitness but also to reduce disease activity in some cases of rheumatoid arthritis. ${ }^{2-4}$ Shortly after Tegner's visit Professor Nanna Svartz initiated the design by Pharmacia of sulphasalazine, a drug ignored for many years by Swedish (and other) rheumatologists.

Turning to more recent areas of scientific progress, it was in Uppsala that Lars Klareskog described the characteristics of DR expression on cells in inflamed tissues in skin and synovium. ${ }^{5}$ His pupil Rikard Holmdahl later studied experimental arthritis, in particular the collagen arthritis in mice, and elucidated many secrets of this model, not least the precise molecular requirements for arthritogenesis. ${ }^{6}$ The role of collagen II as potential driving autoantigen in human arthritis remains, however, controversial.

Another major constituent of articular cartilage, proteoglycan, was the basis of Dick Heinegard's thesis in 1974, and he and his group have over a number of years described and cloned an impressive number of matrix constituents and are trying to elucidate their functional organisation. ${ }^{7}$ An application of novel information on matrix composition is the development of sensitive immunoassays for cartilage derived macromolecules in synovial fluid and circulation by Saxne. ${ }^{8}$

Twenty five years ago the anatomist. Per Ingvar Brånemark of Gothenburg introduced a daring technique of osseo-integrated implantation using titan screws. Overcoming great initial scepsis, the method is now accepted world wide to anchor teeth, and promising early results are being gathered in finger joint replacement. The nickel-bone interface seems to have a remarkable antimicrobial effect promoting the healing. These examples serve to illustrate the close connections between clinical rheumatology and basic science advance. The facilitation of such communication is one important task for good journals like the Annals. I wish the editor good luck and continued success.

FRANK A WOLLHEIM Department of Rheumatology University Hospital of Lund $S-22185$ Lund Sweden

1 Tegner W S. Treatment of rheumatic diseases in United States and continent of Europe. Ann Rheum Dis 1939; 1: 249-303.

2 Nordemar R, Ekblom B, Zachrisson L, Lundqvist $\mathrm{K}$. Physical training in rheumatoid arthritis: a controlled longterm study. I. Scand 7 Rheumatol 1981; 10: 17-23.

3 Danneskiolde-Samsøe B, Lyngberg K, Risum T, Telling M The effect of water exercise therapy given to patients with The effect of water exercise therapy given to patients with
rheumatoid arthritis. Scand f Rehabil Med 1987; 19: 31-5. rheumatoid arthritis. Scand f Rehabil Med 1987; 19: 31-5.
Ekdahl C, Andersson S I, Moritz U, Svensson B. Dynamic Ekdahl C, Andersson S I, Moritz U, Svensson B. Dynamic
versus static training in patients with rheumatoid arthritis. versus static training in patients with

Scand f Rheumatol 1990; 19: 17-26.
5 Klareskog L, Forsum U, Malmnäs Tjernlund U K, Kabelitz D, Wigren A. Appearance of anti-HLA-DR-reactive cells in normal and rheumatoid synovial tissue. Scand $\mathcal{f}$ Immunol 1981 ; 14: 183-92.

6 Holmdahl R, Karlsson M, Andersson M E, Rask L, Andersson $L$. Localization of a critical restriction site on the I-A beta chain that determines susceptibility to collagen-induced arthritis in mice. Proc Natl Acad-SciUSA 1989; 86: 9475-9.

7 Heinegard D, Oldberg A. Structure and biology of cartilage and bone matrix noncollagenous macromolecules. FASEB and 1989; 3: 2042-51.

8 Saxne $T$, Heinegård D, Wollheim F A, Pettersson $H$. Difference in cartilage proteoglycan level in synovial fluid in early rheumatoid arthritis and reactive arthritis. Lancet in early rheum ii: $127-8$.

\section{Spain: Rheumatologists' training}

Training of a specialist in rheumatology takes four years. In 199029 hospitals had teaching 
authorisation. For a hospital rheumatology unit to be recognised as adequate it must meet the requisites evaluated by the National Committee of the Specialty of Rheumatology.

Education of rheumatology students comprises both general and specific training.

For the general educational stage a wide training in internal medicine and those subspecialties closely related is considered essential. Its duration ranges between 12 and 24 months. Each hospital has designed a rotative programme in several services related to internal medicine; two or three months or more is spent in each of those services. Trainees develop their skills among inpatients and are integrated into the provision of care and into educational activities. Additionally, throughout their training they are incorporated into the emergency system of the hospital.

During the specific training stage residents acquire knowledge and experience in order to assure their competence as rheumatologists. There is an established programme each year covering theoretical and practical knowledge. During the second year of specialisation (first year in specific training) trainees help care for rheumatic patients in hospital and outpatients with rheumatological conditions, under the surveillance of a senior member of the unit. During the third year students help in the training of new trainees and their responsibilities for care provision are increased; during the fourth year they develop research work related to rheumatology, they are in charge of outpatient and inpatient care, and also supervise the tasks and education of new students.

According to this design, 30 new rheumatologists have been educated each year during recent years. In January 199135 students started their training. At present, new rheumatologists find a job quickly, generally in new rheumatology units or in units which are expanding. Currently, there is some imbalance between the creation of new jobs and the generation of new rheumatologists.

In contradistinction, there is a marked shortage of jobs dedicated to rheumatological research and to training in medical schools, as in several medical schools rheumatology teaching is given by professors of internal medicine and there are few rheumatologists on the teaching staffs of medical schools.

E LIENCE Section of Rheumatology Hospital General Vall d'Hebron Passeig Vall d'Hebron, $s / n$ 08035 Barcelona Spain

\section{Pacific Basin}

It is always a great pleasure to wish an old friend happy birthday, particularly a half century. To rheumatologists around the Pacific rim the Annals is an old friend and has represented the best of clinical and scientific rheumatology for almost half a century. Those of us from the bottom part of the rim (Australia and New Zealand) have a particular affiliation in that many of us did our rheumatology training in Britain and have published in the Annals. British rheumatology, however, has had a much wider influence in the region-in Hong Kong, Singapore, Malaysia, and Japan, for example, with exchange studentship and postgraduate courses.

It is interesting to see just how many Australian and New Zealand rheumatologists did their training in Britain and that tradition continues today with the Michael Mason Fellowships. It was, of course, a British rheumatologist and member of the Empire Rheumatism Council at the time (Dr C B Heald) who stimulated the formation of the Australian Rheumatism Council by the Royal Australasian College of Physicians in 1949. The visit of Dr W S C Copeman to Australia in 1955 was further stimulus to the formation of the Australian Rheumatism Association in $1956 .^{1}$ Early and later Australian rheumatologists trained under Eric Bywaters, Barbara Ansell, Watson Buchanan, and Professor Kellgren. The number of trained rheumatologists in Australia ${ }^{2}$ has doubled over the last 10 years and continues to increase, with a significant postgraduate training component obtained in Britain. The three professorial appointees in Australia have all had a British training so Australia, in particular, owes British rheumatology a great deal.

Obviously things have changed though. Rheumatology research in Japan, Australia, and New Zealand is extremely active, and young British rheumatologists could gain a great deal from a year or two in this part of the world. Fascinating areas of research are still available in places like Papua New Guinea where John Richens, a young English doctor, spent five years researching seronegative arthritis in the Highlands around Goroka. Large populations of patients with systemic lupus erythematosus are found in Singapore, Hong Kong, and China. Rheumatological rarities such as KashinBeck disease are found in China and need enthusiastic minds to sort out. Many countries in and around the Pacific rim would welcome exchange visits from young rheumatologists wishing to expand their horizons.

The big challenges for rheumatology in this part of the world are probably in the area of community education and epidemiology. The COPCORD project has been developed under the Asia/Pacific League Against Rheumatism to look at the incidence of rheumatic diseases in the Phillipines, in Indonesia, and more recently has been extended to an urban population in Melbourne. It is hoped to expand this to a population in Singapore and to an urban population in the Phillipines. Research potential in China is enormous with studies of systemic lupus erythematosus in Shanghai and general rheumatic diseases in Manchuria (Edmonds J, ARA scientific meeting, Brisbane, 1989).

In an effort to stimulate more epidemiological research young rheumatologists are encouraged to train at the Rockefeller Foundation courses available in Toronto and Hamilton in Canada, Chapel Hill and Philadelphia in the United States, and Newcastle in Australia. Through the 
international clinical studies and drug control committee of APLAR it is hoped to carry out clinical trials of new antirheumatic drugs, observing if different populations within the area will respond in different ways to those agents.

With modern communication the world is becoming an ever smaller place, and it is hoped that over the next 50 years the rheumatological flow from this part of the world towards Britain will be somewhat reversed and the expertise that British rheumatology obviously still has will flow outwards towards the periphery and help us to develop our area rheumatologically.

1 Sherrington G. Rheumatology in Australia-the role and development of the Australian Rheumatism Association. Sydney: Hale and Iremonger, 1990.

2 Report of APLAR standing committee. APLAR Bulletin, 1990; 8: 7 .

PETER BROOKS

Department of Rheumatology Royal North Shore Hospital St Leonards NSW 2065

Australia 